\title{
A two-level description of Old Church Slavonic morphology
}

\section{Lindstedt, Jouko}

1984

Lindstedt , J 1984 , ' A two-level description of Old Church Slavonic morphology ' , Scando-Slavica, no. 30 , pp. 165-189 .

http://hdl.handle.net/10138/33846

acceptedVersion

Downloaded from Helda, University of Helsinki institutional repository.

This is an electronic reprint of the original article.

This reprint may differ from the original in pagination and typographic detail.

Please cite the original version. 


\section{A Two-Level Description of Old Church Slavonic Morphology}

\section{INTRODUCTION}

This article presents a new type of synchronic morphological description of Old Church Slavonic (OCS). It is based on a computational two-level model created by Kimmo Koskenniemi (1983). The main characteristics of this model are as follows:

(1) A language is described morphologically by means of two-level rules which define the permissible correspondences between the lexical and surface representation of a word form. No intermediate representations like those used in generative phonology are needed.

(2) The model does not distinguish between production and recognition: the rules are not directional.

(3) The model is implemented as a computer program which, given a morphological description of a language, can both produce (generate) and recognize (analyse) word forms of that language.

The model is described in detail by Koskenniemi (1983); Karttunen (1983) can also be consulted. Koskenniemi has written a computationally effective implementation of his model in the PASCAL programming language; there is also an INTERLISP implementation (Gajek et al. 1983). Koskenniemi's book contains a full morphological analysis of Finnish in terms of two-level rules. Similar descriptions of English, French, Rumanian and Japanese can be found in Vol. 22 (1983) of the Texas Linguistic Forum. Analyses of Swedish, Modern Greek and Classical Arabic are being prepared at the University of Helsinki.

Below I present my two-level description of OCS and demonstrate how the automatic analysis of word forms works (their automatic generation is a simpler job and will not be discussed). Notational conventions of two-level morphology and its other general features will be introduced in the course of the presentation.

What use can be made of such a computer model of OCS? First, it is a linguistic description, just like any other morphological (e.g. generative) 
description. But it is easier to test because its correctness can be checked by executing the program. Secondly, the model can be used for philological purposes like tagging and lemmatizing ${ }^{1}$ computerized OCS corpora (once such corpora have been established). Thirdly, OCS is a suitable testing ground for the morphological rules needed in describing all modern Slavonic languages, whose automatic analysis would have numerous scientific and commercial applications.

\section{THE PRESENT STATE OF THE OCS MODEL}

The test dictionary and rule component of the OCS description have been chosen to permit experimentation with (i) all the main declensional and conjugational types and (ii) all the productive morphophonological rules. The full paradigms of different types of nouns and verbs and the definite and indefinite declension of the adjective have been implemented. The comparison of adjectives has not been included here, but this should not be more difficult to implement than the participle formation of verbs, which already works correctly. Numerals have not yet been incorporated into the system. As regards pronouns, the system now recognizes the main declensional type $t z$, togo and its soft counterpart moi, mojego.

All the lexemes of the test dictionary are listed below to show the inflectional types the present system can handle:

biti, bogъ, brati, cěsar's, crъky, čajati, čisti, čuti, chvaliti, dělati, dъnь, dobl's, duchъ, duša, dъšti, dvignęti, glagolati, glagolъ, graždaninъ, greti, gъnati, igo, imę, jędza, jęti, kamy, k'esar'b, kon's, kostı, kopati, krai, krъvь, kryti, kъnędzь, kъn'iga, lěto, lъgati, mati, minǫti, moi, mošti, mǫžb, mysliti, myslı, narešti, naricati, nastaviti, nesti, noga, novъ, otьcь, otročę, qže, padati, pasti, pęti, pluti, pol'e, pǫtı, prěbiti, rabъ, rešti, rọka, sěsti, sěti (and sějati), slovo, slyšati, smbjati, strada, stradati, synъ, tъ, tešti, teti, tělo, tokъ, tъštı, velěti, velii, vesti (vedQ), věrovati, viděti, vъzvěstiti, vyšsn'b, zeml'a, zmija, znamenije, znati, zъvati, žena, žęti, žrěti.

\footnotetext{
"Morphological tagging means providing the words of a corpus with "tags" indicating their morphological and morphosyntactic analysis, which enable the user to search automatically, say, for all feminine accusative forms. Lemmatizing assigns each word form a lemma, i.e. its dictionary headword (or other conventional name of the lexeme), and is useful for compiling concordances, etc.
} 
The system is a kind of "computerized Leskien"-i.e. it knows the standard paradigms and morphophonological alternations found in classical Handbücher like Leskien's (1969) and Vaillant's (1964). The surface representations of the words are transliterations of their Cyrillic orthography, with certain graphemic variations taken into account. As not all computers can yet handle diacritics easily, I have substituted capital letters for the missing characters: $A=\check{e}, E=e ̨, O=q, I=\mathbf{b}, U=\mathbf{b}$; $S=\check{s}, Z=\check{z}, C=\check{c}$. For ch $I$ have used $x$ (h would have done equally well since it has no other uses), and $\mathrm{dz}$ is represented by $\mathrm{D}$. The palatalization sign ' ( ) after $\mathrm{n}, \mathrm{l}, \mathrm{r}, \mathrm{ch}, \mathrm{k}$, and $\mathrm{g}$ is marked by '. In the present article this transliteration is used only when parts of the computer files are quoted directly. Otherwise I have employed the traditional system with diacritics. For ch and $\mathrm{dz}$, however, $\mathrm{I}$ have had to use $\mathrm{x}$ and $\mathrm{D}$ because digraphs would have spoiled the vertical alignment of the two-level rules.

The system knows that $\mathbf{j}$ can appear optionally after all palatal consonants (including $\check{s}, \check{z}$, c, etc.), and can even replace the palatalization sign. It also knows that $\mathrm{j}$ is only permissible before certain vowels; combinations such as $*_{\text {jo }}$ are impossible.

An interactive session with the computer (Burroughs $\mathrm{B} 7800$ ) is presented in the Appendix as an example. It shows that the system can cope with the homography of forms of different lexemes, and with syncretism within paradigms.

The morphological system that makes the automatic analysis of OCS word forms possible consists of two files, a dictionary file and an automata file, the latter simulating two-level rules. Technically, these are data files: the description is not part of the program code, which is why the two-level program can be used to describe any language and differs essentially from language-specific systems like that presented in Sågvall (1973). The two data files are discussed below consecutively.

\section{THE DICTIONARY}

In the two-level descriptions, the dictionary consists of a number of lexicons and definitions of continuation classes. The longest lexicon is the Root lexicon containing the roots of all the lexemes. The other lexicons comprise (a) stem alternation patterns, and (b) suffix sets. In every lexicon, the format of the lexical entries is

(lexical representation) (continuation class) "(meaning)", 


\section{Jouko Lindstedt}

For example, the Root lexicon includes the following entry:

slov o/es "word N $\langle\mathrm{NE}\rangle$ ";

which means that slov is a neuter noun meaning 'word' and belonging to the continuation class o/es. This continuation class is defined as a pointer to a lexicon called o/es (it happens to have the same name as the class but this is not indispensable). The lexicon o/es contains the following entries:

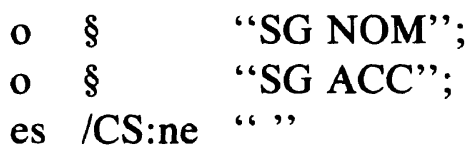

All $s$ stems refer to this same lexicon, so their typical alternation pattern need be presented only once. The sign $\S$ denotes the end of the word, i.e. the continuation class with no pointers to other lexicons. The string es has no meaning of its own but its continuation class is /CS:ne ('neuter consonant stem'), which is defined as a pointer to the lexicons CS:sg (singular consonant-stem endings common to all three genders), CS:pl (the corresponding plural and dual endings), and CS:ne (endings proper to the neuter consonant stems only). For example, the lexicon CS:sg appears as follows:

$$
\begin{aligned}
& +\mathrm{e} \S \text { "SG GEN"; } \\
& +\mathrm{i} \S \text { "SG DAT", }
\end{aligned}
$$

If a stem is not subject to alternations other than those specified by the two-level rules (see below), the continuation class of the root points directly to the suffix lexicons, e.g. the o-stem $r a b$ :

rab lo:ma "slave $\mathrm{N}\langle\mathrm{MA}\rangle$ ”;

Thus, the dictionary consists of a complicated network of lexicons, held together by the continuation class definitions. It is easy to see how this system can be used to describe, say, the different declensions of nouns, so I will not go into greater detail. Some interesting points can be noted, however.

To start with, the dictionary does not need to know the distinction between "hard" and "soft" endings, so fewer paradigms are required than in OCS Handbücher. The surface string kon'b 'horse' (nom. and acc. sg., and gen.pl.) is paired with the lexical string $k o n^{\prime}+z$. The 
relation $\measuredangle \leftrightarrow b$ is handled by the "vowel-fronting" two-level rule (rule (5a) below).

Adjectives make use of the existing lexicons of nominal and pronominal endings. The continuation class /Adj points to the lexicon Adj, which looks like this:

\begin{tabular}{|c|c|c|}
\hline$\emptyset$ & /o:ma & "'INDEF $\langle\mathrm{MA}\rangle$ ", \\
\hline$\emptyset$ & $/ a$ & “'INDEF $\langle\mathrm{FE}\rangle\rangle^{\prime}$, \\
\hline 0 & /o:ne & "INDEF $\langle\mathrm{NE}\rangle$ "'; \\
\hline$+\% \mathrm{Uj}$ & /Pron & “'DEF"'; \\
\hline$+\%$ yj & /Pron & "DEF"'; \\
\hline$+\% \mathrm{Yj}$ & /Pron & "'DEF"; \\
\hline$+\%$ aj & /Pron & “DEF”; \\
\hline$+\%$ uj & /Pron & "DEF"'; \\
\hline$+\% \ddot{\mathrm{Aj}}$ & /Pron & "DEF"'; \\
\hline$+\% o j$ & /Pron & "DEF"'; \\
\hline$+\% \mathrm{Oj}$ & /Pron & "'DEF"; \\
\hline$+\% \mathrm{ij}$ & /Pron & "DEF"; \\
\hline$+\%$ & /Pron & “DEF"' \\
\hline
\end{tabular}

The first three entries add no characters to the lexical representation; they merely refer to the suffix lexicons of o- and a-stems. The other ten entries represent case ending remnants which (together with the old pronominal stem $j$-) are to be found in the definite adjective forms in front of the pronominal endings (to which /Pron points). (The morphophonemes $\ddot{A}$ and $Y$ are explained in section 4.) The sign "\%" is a morphological feature triggering a two-level rule according to which every case-ending remnant must be followed by the correct pronominal endings. The string $+\% U j$ is paired only with pronominal endings which have the feature " 1 ", +\%yj only with those marked " 2 "' and so on. The alternative would have been to assign a separate continuation class to each of the ten case-ending remnants and divide the now unitary Pron lexicon into corresponding smaller lexicons. The present treatment is preferred because the pronominal declension by itself forms a neat paradigm; it is the definite adjective declension that is messy in OCS (corresponding synchronically to the diachronic flux).

In the case of verbs, it is interesting to note that there are no really separate conjugations in the same way as there are separate declensions of nouns. All the verbs share the same set of suffix lexicons. The only exceptions-not counting the few athematic verbs-are the endings of 
tense, which

- three

ted for

ited as

'suffix

lasses.

əd in a

ati 'to

of the

-iting a

$d$ then

of this

nation

suld be

sion in

corre-

f each

several

icter B

- Note

er this

erative

I class it revious e, the !J dings of 
rules are ordered in series, while two-level rules operate in parallel: each word-form must satisfy all of them simultaneously (provided the context specifications are met). Two-level rules also give wider possibilities for context specification. Actually, rule (ii) is merely an abbreviation of

(iii) $\begin{aligned} & \mathrm{A} \\ & \mathrm{B}\end{aligned} \Leftrightarrow \begin{aligned} & \mathrm{C} \\ & \mathrm{C}-\mathrm{D}\end{aligned}$

and nothing prevents us from writing rules like

$$
\text { (iv) } \begin{aligned}
& \mathrm{A} \\
& \mathrm{B}
\end{aligned} \Leftrightarrow \mathrm{C}
$$

i.e. "A corresponds to $\mathrm{B}$ if, and only if, it follows a $\mathrm{C}$ that corresponds to G (according to some other rule)". Optionality of a surface realization is marked by making the context condition a necessary but not sufficient condition, i.e. by using the $\Rightarrow$ ('only if') operator instead of $\Leftrightarrow$.

For example, to describe the correspondence ved $+t i \leftrightarrow v e s t i$ 'to take (someone somewhere)', we need the following rules:
(v) ${ }_{s}^{d} \Leftrightarrow \ldots+t$
(vi) ${ }_{\emptyset}^{+} \Leftrightarrow$

The latter rule deletes the morpheme boundary in all contexts. (For the actual formulation of these rules, see $(10 a)$ and ( $4 b)$ below.) Taken together, (v) and (vi) allow the following pairing of lexical and surface strings:

$$
\begin{aligned}
& v e d+t i \\
& \text { ves } 0 t i
\end{aligned}
$$

which is just what we want.

The two-level program does not yet understand two-level rules, as such, but only special matrices representing finite-state automata that simulate the rules. It is psycholinguistically interesting to note that the rules are equivalent to such computationally simple and effective devices (cf. Koskenniemi 1983: $134 \mathrm{ff}$. on processability). The exact form of the automata is not of great linguistic interest because all the rule automata could in principle be merged into one big automaton representing all the rules, whereas the rules themselves cannot coalesce in the same way. Below, I will not present the contents of the automata file, but I will describe the rules that the automata encode. 


\section{Jouko Lindstedt}

To start with, the alphabet to be used in the rules must be specified. It contains all the surface characters from a to ž, including the 'sign, and morphophonemes, junctures, and feature signs. There are six morphophonemes:

Y: suffixal y whose soft counterpart is ę

Ä: "Jat-2"

$\mathrm{H}$ : $\mathrm{b}$ which is in an Ablaut relation to $\mathrm{i}$

\&: the ending of the aorist 2 nd and 3 rd p. sg.

S: the consonant in the sigmatic aorist

$\mathrm{J}$ : underlying " $\mathrm{j}$ " which is never realized as such but alters the previous consonant

There are two morphological junctures: the ordinary morpheme boundary " +", and the juncture " " " used in the past participle passive as its distinctive mark (i.e. to encode both the juncture and a morphological feature). A dozen more signs, such as "!", "(" and "“", are used as morphological features in the lexical representations.

The context specifications of the rules have been simplified by defining subsets of the alphabet. I have used the following:

$=$ : all the characters of the alphabet

$\mathrm{K}$ : consonants $\left(\mathrm{b} \mathrm{c} \check{c} \ldots \mathrm{z} \check{\mathrm{z}}^{\prime} \dot{S}\right.$ )

V: vowels (a e ... y Y Ä H \&)

P: palatal consonants (' j J š ž č c D)

$W$ : vowels before which a $j$ can be written ( $\mathrm{a}$ e eq $\mathrm{Q} u$ )

M: vowels triggering the first palatalization (b e ę è \&)

$\mathrm{N}$ : vowels triggering the second palatalization (i $\ddot{\mathrm{A}})^{3}$

B: labials ( $\mathrm{p} \mathrm{b}$ $\mathrm{m})$

$\mathrm{Q}$ : velars $(\mathrm{k} \mathrm{g} \mathrm{x})$

L: dental sonorants $(\mathrm{l} n \mathrm{r})$

These sets can only refer to concrete correspondence pairs established by other rules, which is why a context condition like

$$
\mathrm{t}=\mathrm{t}
$$

does not mean "between two t's that can each be realized as any character" but "between two t's that are realized as defined by other rules"'. In most cases this actually means

${ }^{3}$ In the endings, $\mathrm{i}$ is always an $\mathrm{i}_{2}$, so it can be placed in set $\mathrm{N}$. 


$$
t-t(\text { i.e. } t-t)
$$

but context specifications are usually not made so redundant (though this is also a matter of style).

The rules are as follows:

(1) Surface characters

$$
\text { (1 a) } \underset{\mathrm{a}}{\mathrm{a}} ;{ }_{\mathrm{b}}^{\mathrm{b}} ; \ldots ; \underset{\mathrm{z}}{\check{\mathrm{z}}} \Rightarrow
$$

This rather trivial rule defines the characters that can surface as such in any context, but they must be realized as something else if another rule so specifies; that is why the context condition is only necessary (" $\Rightarrow$ ") but not sufficient (" $\Leftarrow$ "). I have used semicolons to merge rules in an obvious fashion.

$$
\text { (1b) }, \Rightarrow[\mathrm{L} \mid \mathrm{Q}]
$$

' can only appear after $1, \mathrm{n}, \mathrm{r}, \mathrm{k}, \mathrm{g}$, or $\mathrm{x}$. The notation $[\ldots \mid \ldots]$ is used to mark alternative parts of the context.

(2) Graphemic options for soft consonants

$$
\text { (2a) }{ }_{\mathrm{j}}^{\prime} \Rightarrow
$$

According to the rule, ' can always be realized as $\mathbf{j}$ (but note that rule ( 3 a) may prevent this in specific cases).

$$
\text { (2b) } \underset{j}{+} \Rightarrow\left[\begin{array}{c|c|c|c}
== & == & = & D \\
\check{s} ~ & \check{z} d & P & z
\end{array}\right] \text { - }
$$

The morpheme boundary can correspond to $\mathrm{j}$ if it follows anything that is realized on the surface as št, žd or a palatal consonant, including $\mathrm{z}$ representing $\mathrm{D}$. This rule accounts for the graphemic variation možal mqžja 'man (gen.sg., nom.dl.)' and similar cases. As the two-level model does not allow for absolute epenthesis ( $\emptyset$ is only permitted on the surface level), the epenthetic $\mathrm{j}$ must technically be taken from the boundary mark.

(3) The graphemics of $j$

$$
\text { (3a) }{ }_{\mathrm{j}}^{=} \Rightarrow-\mathrm{W}
$$


(3b) $\underset{\emptyset}{\mathrm{j}} \Leftrightarrow-\mathrm{i}$

An example: in the locative $k r a j+\ddot{A}$ 'edge', $\ddot{A}$ becomes $\mathrm{i}$ according to rule ( $5 \mathrm{~b}$ ); but in this case the context condition in ( $3 b)$ is met, $j$ disappears, and we obtain the surface form krai.
(3c) ${ }_{\mathrm{i}}^{\mathrm{b}} ; \stackrel{\mathbf{b}}{\mathrm{i}} \Leftrightarrow \stackrel{\mathrm{j}}{=}$
(3d) $\underset{\emptyset}{\mathrm{j}} \Leftrightarrow \underset{\mathrm{j}-}{=}$

Logically, rules ( $3 b$ ) and ( $3 d$ ) only make sense if their context conditions are understood to be in a disjunctive relation. This is a general convention of the two-level model (Koskenniemi 1983: 37-38).

(4) Unmarked realizations

(4 a) $\underset{\mathrm{D}}{\mathrm{D}} ; \frac{\mathrm{D}}{\mathrm{z}} ; \underset{\mathrm{y}}{\mathrm{Y}} ; \underset{\mathrm{e}}{\ddot{A}} ; \underset{\mathrm{b}}{\mathrm{H}} ; \underset{\mathrm{e}}{\&} ; \stackrel{\dot{\mathrm{S}}}{\mathrm{s}} ; \underset{\emptyset}{\mathrm{J}} \Rightarrow$

This rule defines the "context-free" realizations of the morphophonemes and allows D to surface either as D or as $\mathrm{z}$.

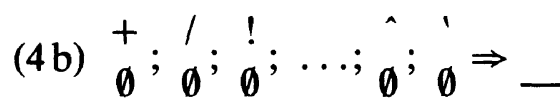

Junctures and feature signs are always realized as a zero string. The only exceptions are cases in which they are used as placeholders for epentheses, as in rule $(2 \mathrm{~b})$ above.

(5) Vowel fronting

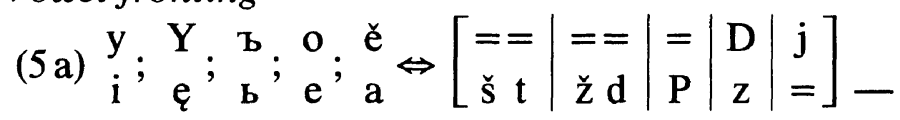

This rule produces the endings of "soft" declensions, ${ }^{4}$ among other things. Note how (5a) and (7a) interact in the imperfect tečaaxz 'I was running':

$$
\begin{aligned}
& \mathrm{t} \text { e. } \mathrm{k}+\check{\mathrm{e}} \mathrm{a} \times \mathrm{x} \mathrm{b} \\
& \text { t e } \emptyset \text { c } \emptyset \text { a } a \times \text { b }
\end{aligned}
$$

By a general convention of the two-level model (Koskenniemi 1983: 40),

${ }^{4}$ For the $\mathrm{e} \leftrightarrow \mathrm{a}$ correspondence the term "fronting" is not justifiable phonetically, but it is included in the fronting rule owing to its identical context conditions. 
intervening junctures and feature signs- " + " in this example-need not be mentioned in the context conditions of rules if they are optional.

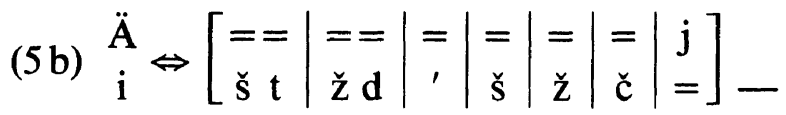

$$
\begin{aligned}
& \text { (5c) } \underset{\mathrm{i}}{\ddot{A}} \Leftrightarrow\left[\begin{array}{l|l}
\mathrm{c} & \mathrm{D} \\
\mathrm{c} & =
\end{array}\right]=-
\end{aligned}
$$

The context condition for the $\ddot{A} \leftrightarrow \mathrm{i}$ correspondence resembles that of the general fronting rule ( $5 \mathrm{a}$ ) but there is an important exception: after $\mathrm{c}$, $\mathrm{D}$ and palatalized $\mathrm{z}$, this correspondence only holds good (i) if a c or D appears at the lexical level too, and (ii) if there is a morpheme boundary between this character and $\ddot{\mathrm{A}}$. The need for the first condition can be seen by comparing the locative singulars otbci 'father' and tocé 'flow', or kъnęzi 'prince' and bozě 'god'. The second condition is necessary to "protect"' such words as cělı 'healthy'. (So this root must be represented lexically as $c \ddot{A l}$, because the form cĕl would surface as ${ }^{*} c a l$. If a representation like $k \ddot{A} l$ were used, the morpheme boundary condition in (5c) would not be necessary-but this solution would be too abstract from a synchronic point of view.)

(6) Choices conditioned by lexical softness

$$
\begin{aligned}
& \text { (6a) } \stackrel{(}{=} \Rightarrow\left[\begin{array}{c|c|c}
\check{s} \mathrm{t} & \check{z} \mathrm{~d} & \mathrm{P}^{\prime} \\
== & == & =
\end{array}\right] \text { - }
\end{aligned}
$$

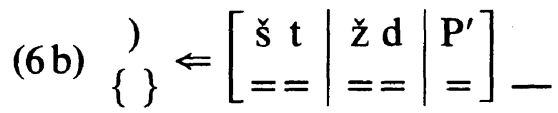

where $\mathrm{P}^{\prime}$ is identical to $\mathrm{P}$ except that $\mathrm{c}$ and $\mathrm{D}$ are excluded. According to this rule, the feature "(" can only occur after palatal consonants of the lexical level; ")" cannot occur in the same context ( \{\} is the empty set: ")" cannot correspond to anything, not even to the zero string $\emptyset$ ). The two feature signs are used in the o-stem vocative endings to account for the difference between rabe 'slave' and mqžu, mQžju 'man', which is not due to the vowel fronting rules.

(7) Palatalization of velars

$$
\begin{aligned}
& \text { (7 a) } \underset{\mathrm{c}}{\mathrm{k}} ; \underset{\mathrm{z}}{\mathrm{g}} ; \stackrel{\mathrm{s}}{\mathrm{s}} \Leftrightarrow-\left[\begin{array}{l|l}
\mathbf{M} & \mathrm{J} \\
= & =
\end{array}\right] \\
& \text { (7b) } \underset{\mathrm{c}}{\mathrm{k}} ; \mathrm{D} ; \mathrm{z} ; \mathrm{s} \Leftrightarrow-\left[\begin{array}{l}
\mathrm{N} \\
=
\end{array}\right]
\end{aligned}
$$


(7c) $\underset{\check{c}}{\stackrel{\mathrm{c}}{\mathrm{c}} ; \stackrel{\mathrm{D}}{\check{\mathrm{Z}}}} \Leftrightarrow-\left[\begin{array}{l|l}+\mathrm{M} & \mathrm{J} \\ == & =\end{array}\right]$

(For (7c), cf. vocatives otbče 'father', kъnęže 'prince'.)

(8) Consonant $+J$ (excluding velars) ${ }^{5}$

(8a) $\stackrel{\mathrm{t} !}{\mathrm{s} t} ; \stackrel{\mathrm{d} !}{\mathrm{z} \mathrm{d}} \Leftrightarrow \underset{\mathrm{J}}{\mathrm{J}}$

"'!' is a sign that always precedes $\mathbf{J}$ at the lexical level and is used as a place-holder in epenthesis.

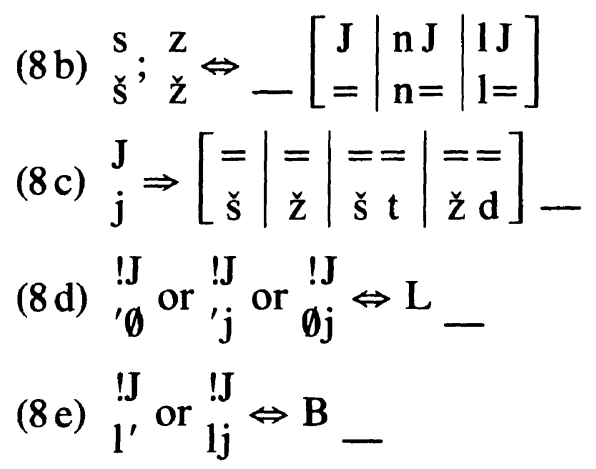

Note that, since !J is most often followed by " + ", the third graphemic possibility after a labial consonant, viz. $l^{\prime} j$, follows from ( $\left.2 \mathrm{~b}\right)$ (e.g.

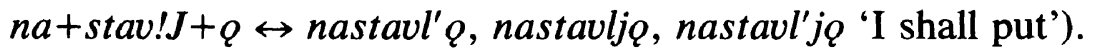

(9) Consonant alternation in the verb stem, I: velars and labials ${ }^{6}$

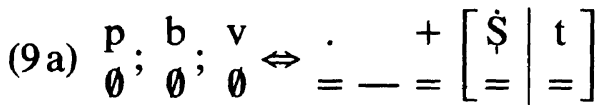
(9b) $\begin{aligned} & \mathrm{k} \\ & \emptyset\end{aligned} \underset{\emptyset}{\mathrm{g}} ; \underset{\emptyset}{\mathrm{x}} \Leftrightarrow \stackrel{+\dot{S}}{=-=}$

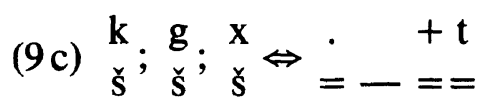

5 The use of a sequence of correspondence pairs in the correspondence part (left-hand side) of a rule must be regarded as a condensation of rules in which each of these pairs appears in the correspondence part in turn, the others being in the context-condition part.

${ }^{6}$ Actually the rules (9a) ... (9c) are implemented as if they were as follows:

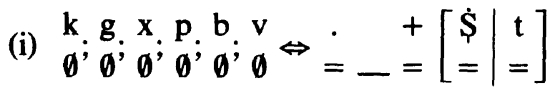

(ii) $\stackrel{+}{\mathrm{s}} \Leftrightarrow\left[\begin{array}{l|l|l}\mathbf{k} & \mathbf{g} & \mathbf{x} \\ = & = & =\end{array}\right]$ t 
The sign "." is put in the lexicon before the stem-final consonant of every verb having a consonantal stem in the infinitive and aorist. This is merely an implementational feature: since the automata simulating the two-level rules proceed from left to right, the automaton implementing (9a) and (9b) would try to delete every single velar and labial of every word and only after checking the right context would it realize that it was the wrong alternative. The automaton would work even without the ".," trigger; its sole purpose is to make the computation more efficient. (This sign is used in rule ( $14 \mathrm{a})$ to identify a certain class of verbs, because it already exists.)

(10) Consonant alternation in the verb stem, II: dentals

$$
\begin{aligned}
& \text { (10a) } \begin{array}{l}
\mathrm{t} \\
\mathrm{s}
\end{array} \stackrel{\mathrm{d}}{\mathrm{s}} \Leftrightarrow=\begin{array}{l}
\cdot+\mathrm{t} \\
=-=
\end{array} \\
& \text { (10b) } \stackrel{\mathrm{t}}{\emptyset} ; \stackrel{\mathrm{d}}{\emptyset} \Leftrightarrow \stackrel{+}{=}+\left[\begin{array}{c|c}
\dot{S} & 1 \\
= & =
\end{array}\right] \\
& \text { (10c) } \stackrel{s}{\emptyset ;}, \begin{array}{l}
z \\
\emptyset
\end{array} \stackrel{+}{=}+\dot{S} \\
& \text { (10d) } \begin{array}{l}
\mathrm{z} \\
\mathrm{s}
\end{array}=-\quad+\mathrm{t}
\end{aligned}
$$

Rule ( $10 \mathrm{~d})$ is, of course, a special case of voice assimilation but no such general rule of assimilation is needed in the synchronic system.

(11) Consonant alternation in aorist endings

$$
\text { (11 a) } \begin{aligned}
& \dot{S} \\
& \mathrm{X}
\end{aligned} \Leftrightarrow\left[\begin{array}{l|l}
\mathrm{Q} & \mathrm{V}^{\prime} \\
= & =
\end{array}\right]=-\mathrm{V}^{\prime}
$$

where $V^{\prime}=a$ vowel other than ę.

$$
\text { (11b) } \begin{aligned}
& \dot{\mathrm{S}} \\
& \check{\mathrm{s}}
\end{aligned} \Leftrightarrow\left[\begin{array}{l|l}
\mathrm{Q} & \mathrm{V}^{\prime} \\
= & =
\end{array}\right]=-\mathrm{e}
$$

Note that $\dot{S} \Leftrightarrow s$ is the default case according to rule (4a).

$$
\begin{aligned}
& \text { (11c) }{ }_{\mathrm{x}}^{\dot{S}} \Rightarrow \begin{array}{l}
\mathrm{e}+ \\
==-\mathrm{V}^{\prime}
\end{array} \\
& \text { (11d) } \underset{\check{s}}{\dot{S}} \Rightarrow \begin{array}{l}
\mathrm{e}+ \\
==-\mathrm{e}
\end{array}
\end{aligned}
$$

(11 c) and (11d) account for the variation pęsz/pęxz 'I stretched' and pęsę / pęše 'they stretched'. 
(12) Aorist Ablaut

$$
\text { (12 a) } \underset{\mathrm{e}}{\mathrm{e}} ; \stackrel{\mathrm{o}}{\mathrm{a}} ; \stackrel{\mathrm{H}}{\mathrm{i}} \Leftrightarrow-\begin{array}{r}
\mathrm{K}+\dot{\mathrm{S}} \\
\emptyset==
\end{array}
$$

Example: $n e . s+\dot{S} \measuredangle \leftrightarrow n e \check{s} ъ$ 'I carried'.

(13) Avoiding the hiatus in aorist and imperfect endings

$$
\text { (13a) } \stackrel{\&}{\emptyset} ; \stackrel{\check{\emptyset}}{\emptyset} \Leftrightarrow \begin{aligned}
& =+ \\
& \mathrm{V}=-
\end{aligned}
$$

In the dictionary the imperfect endings appear only in their full forms éaxъ, etc., and \& is realized as e by default. If the stem ends in a vowel, this rule deletes the first vowel of the imperfect ending and forces \& to be realized as a zero string.

$$
\begin{aligned}
& \text { rbci 'say!', tbci 'run!', pbci 'bake!' } \\
& (14 \text { a) } \underset{\mathrm{b}}{\mathrm{e}} \Leftrightarrow \quad \text {. k }
\end{aligned}
$$

\section{(15) Blocking verbal endings}

There are two rules whose formalization would be of no use to the reader because they refer to specific feature signs in the dictionary file. The first of these blocks the older type of sigmatic aorist in Leskien's second verb class, permitting dvigz and dvigoxz 'I moved' but not *dvixz. This rule is necessary because it is assumed in the dictionary that all verbs can have this form; only the occurrence of the other two types is regulated by continuation classes.

The second rule blocks certain active past participles 1 , such as * $p e q u$ for pbnz 'having stretched'.

(16) Selecting the case ending remnant in definite adjectives

The purpose of this rule has already been explained in section 3 , in connection with the Adj lexicon.

(17) Coalescing endings in definite adjectives

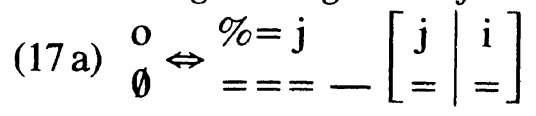

This rule takes care of cases like nov $+\% y j+2 o j \varepsilon \Leftrightarrow$ novyje (the feminine definite genitive singular) and nov $+\% \ddot{A} j+6 o i \Leftrightarrow$ noveri (the feminine definite dative singular). In the case of novyje, the second $\mathrm{j}$ is deleted by (3d). 
(18) Peculiarities of the active participles

(18a) ${ }_{\mathrm{v}}^{*} \Leftrightarrow \begin{aligned} & \mathrm{V}+ \\ & ==-\end{aligned}$

" *"' is a sign used in the present and first past active participles. In the latter, it is used as a placeholder for an epenthetic $v$ if the verb stem ends in a vowel.

Rule (18b) - whose formalization would force us to introduce additional notational conventions-states that no "*" can be followed by a ",", even if there are intervening characters. The feature sign "," is inserted in the nominal and pronominal case endings that cannot be used in the active participles. Thus the participle entries can safely refer to the Adj lexicon after the endings peculiar to participles (e.g. the fem. nom. pl. -i) have been listed.

(19) Allomorphs of the past passive participle

In the dictionary, there are two entries for the formative of this participle: len and $/ t$. The rules of this block define their correct distribution and account for the $\mathrm{e} \Leftrightarrow \emptyset$ correspondence after a vowel. In principle, it would have been possible to use only one lexical entry and write an additional $\mathrm{n} \leftrightarrow \mathrm{t}$ rule, but that would hardly have been a psycholinguistically natural solution.

$$
\text { (19a) } \begin{aligned}
& / \mathrm{t} \\
& ==
\end{aligned} \Rightarrow\left[\begin{array}{l|l|l}
\mathrm{e} & \mathrm{b} & \mathrm{e} \\
= & = & =
\end{array}\right]-
$$

where $e, b$ or ě must be the first vowel of the stem.

$$
\text { (19b) } \begin{gathered}
/ \mathrm{e} \\
==
\end{gathered} \Rightarrow\left[\begin{array}{c|c}
\mathrm{V} & \mathrm{K} \\
= & =
\end{array}\right] \text { - }
$$

where $\mathrm{V}$ cannot be a first-syllable ę or $\mathbf{b}$. These rules must be supplemented by (19c) ... (19e) describing the realizations of the participle formative (note that the default realizations $t$ and $e n$ need not be mentioned):

$$
\begin{aligned}
& \text { (19c) } \begin{array}{l}
/ \\
\mathrm{v}
\end{array} \Leftrightarrow\left[\begin{array}{l|l}
\mathrm{y} & \mathrm{u} \\
= & =
\end{array}\right]- \\
& \text { (19d) } \begin{array}{l}
/ \\
\mathrm{j}
\end{array}=-
\end{aligned}
$$

Condition: the vowels on the right-hand sides of (19c) and (19d) must be in the first syllable. 
(19e) $\begin{aligned} & \mathrm{e} \\ & \emptyset\end{aligned} \stackrel{\mathrm{V} /}{=}$

For the type krbvens 'covered, hidden' (from kry/en $+\varsigma$ ), (19c) must be further supplemented with

(19f) ${ }_{\mathbf{b}}^{\mathrm{y}} \Leftrightarrow-\mathrm{v}$

\section{DISCUSSION}

The present system is satisfactory to the extent it generates and analyses OCS word forms correctly. There are some minor points in which it is overly permissive: it accepts vocatives of all adjectives and some nonexisting definite adjective forms like *veliii 'big'. These flaws are not serious, because the emphasis of the system is on automatic analysis, and not generation.

With greater justification it could be argued that the Cyrillic-based transliteration adopted is not ideal. The attempts to mimic the variable use of the ligatures , etc. and of the ${ }^{-}$sign perhaps make the system unnecessarily complicated. A linguistically more interesting model should be based on descriptions like Trubetzkoy's (1968) and on phonemics that can be reconstructed from the Glagolitic alphabet-with $\Delta, \mathbb{P}$, rendered, say, as ä, ü, $\ddot{Q}$. It may well be that the orthographic conventions of the various codices, including the Cyrillic ones, could be derived more easily from such a "Proto-OCS" description than from the present Cyrillic-normalized version. This question should be studied before any really large dictionaries are converted into the two-level format.

A system containing more lexemes might also benefit if some of the alternation patterns in the present dictionary were converted into rules. These include certain Ablaut patterns (note that the aorist Ablaut is already treated with a rule), ov/u alternations, liquid metathesis, and the alternation between a nasal vowel and the sequence oral vowel + nasal consonant-all features of the verb morphology. But the mere fact that they can be made rules (which I do not doubt) does not necessarily mean that they should be. It is a question either of linguistic naturalness or computational efficiency, or both, depending on the aims of the system; and both these criteria might favour a lexical solution.

Linguistic evaluation of this two-level description is not a simple task. Take the morphophoneme $\mathrm{Y}$, whose function is to mark the y's whose 
"soft" counterpart is ę and not i. Another solution would have been to assume double endings in the relevant cases, )y... and (e..., the selection of which could have been effectively handled by the existing rules $(6 a)$ and $(6 b)$. Thus $Y$ is, in a way, an unnecessary morphophoneme, but by using it we can acknowledge the fact that the y/e alternation is found in several endings and is not arbitrary in the same way as the e/u alternation in the o-stem vocatives (rabe/mqžu).

It is interesting to note that the rules would have allowed much more "abstract" or "archaic" lexical entries than those actually used. Nothing prevents us from relating žena 'woman' to a lexical-level gena, except synchronic plausibility. It would perhaps have been wiser to limit the palatalization rules ( $7 a$ ) and ( $7 b)$ so that they only operated across the morpheme boundaries, as $(7 \mathrm{c})$ already does. In this case we could no longer treat grnati/ženg 'to chase' as an ordinary case of the bna/en alternation pattern but examples of this kind are not numerous.

To sum up, I hope I have shown that Koskenniemi's two-level model is suitable for both the linguistic description and automatic analysis of OCS inflected word-forms and, consequently, for Slavonic morphology in general. Though some of my solutions may prove to be useful in twolevel descriptions of Slavonic languages, all of them will have to be submitted to scrutiny when more lexical material is introduced and the various applications of the analysis are considered.

I wish to thank Kimmo Koskenniemi and Olli Blåberg for their advice and constructive criticism. They share no responsibility for my mistakes.

\section{References}

Gajek, Oliver, Hanno T. Beck, Diane Elder \& Greg Whittemore, "A two-level morphological analyzer: LISP implementation", Texas Linguistic Forum 22, 1983, pp. 187-202.

Karttunen, Lauri, "KIMMO: A general morphological processor", Texas Linguistic Forum 22, 1983, pp. 165-86.

Koskenniemi, Kimmo, Two-Level Morphology: A General Computational Model for Word-Form Recognition and Production, Helsinki 1983 (= Publications of the Department of General Linguistics, University of Helsinki 11).

Leskien, August, Handbuch der altbulgarischen (altkirchenslavischen) Sprache, 9. Aufl. (unveränd. Nachdruck d. 8., verb. u. erw. Aufl. von 1962), Heidelberg 1969.

Sågvall, Anna-Lena, A System for Automatic Inflectional Analysis, Implemented for Russian, Stockholm 1973 (= Data Linguistica 8). 
Trubetzkoy, Nikolaus S., Altkirchenslavische Grammatik, hrsg. von Rudolf Jagoditsch, 2. Aufl. (unveränd. photomechan. Nachdr.), Graz, Wien \& Köln 1968 (=Österreich. Akad. d. Wiss., Sitzungsberichte, Philos-hist. Kl. 228:4). Vaillant, André, Manuel du vieux slave, $2^{\mathrm{e}}$ éd., revue et augm., I: Grammaire, Paris 1964 (=Collection de manuels de l'Institut d'Études slaves 6).

\section{Appendix}

\section{EXAMPLE OF AUTOMATIC MORPHOLOGICAL ANALYSIS}

(The bold-faced lines have been typed by the user, all the others by the system. The comments on the right-hand side have been added to explain what is going on.)

\section{run ŞOCS/TWOL}

§RUNNING 4920

$\S ?$

3

73 Characters in the Alphabet (85)

19 Automata Read In: 1970 States (3000)

125 Rows (200)

287 Columns (300)

(start the program)

(enter the analysis mode) (rule automata read in)

120 Aligned Pairs (200)

67 ALT Lists (150) 191 ALT Items (250)

(dictionary read in)

63 Lexicons Read in (90) 779 Nodes (30000)

716 Branches (30000) 462 Entries (10000)

739 Strings (12000) 6783 Characters (120000)

kamy

kamy

stone N 〈MA〉 SG NOM

kamene

kamen+e

stone $\mathrm{N}\langle\mathrm{MA}\rangle \mathrm{SG}$ GEN

kamen+e

stone N $\langle$ MA $\rangle$ PL NOM

kamen $+\mathrm{e}$

stone N $\langle$ MA $\rangle$ SG LOC (word-form to be analysed) (corresponding lexical representation) (translation, morphosyntactic features)

(next form to be analysed) 


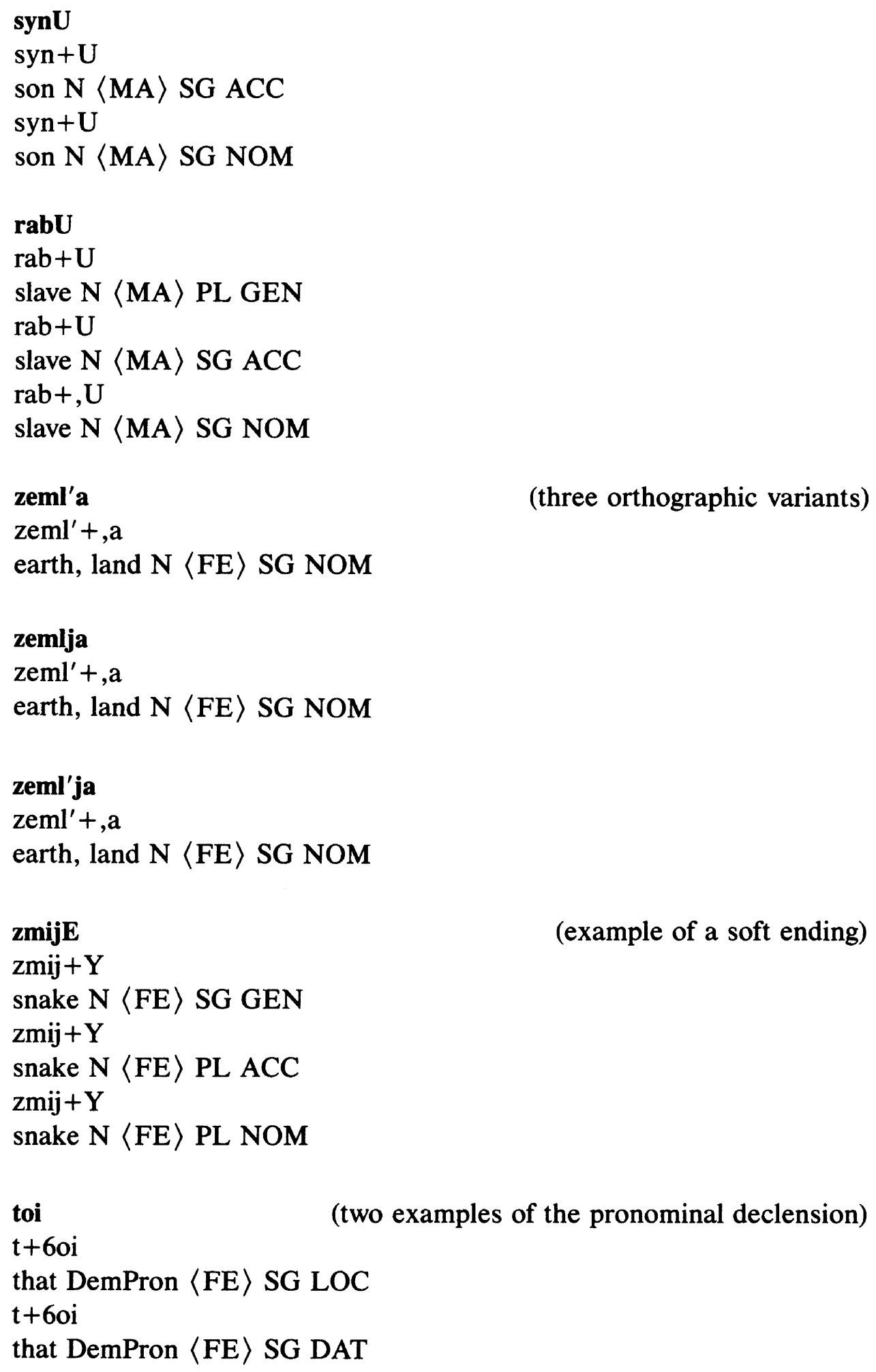

toi

$t+6 o i$ (example of a soft ending) (three orthographic variants) that DemPron $\langle\mathrm{FE}\rangle$ SG LOC $t+6 o i$ that DemPron $\langle\mathrm{FE}\rangle$ SG DAT 
moi

$\operatorname{moj}+6 \ddot{A}$

my PossPron $\langle\mathrm{FE}\rangle$ DL NOM/ACC

moj+6̈̈

my PossPron $\langle\mathrm{NE}\rangle$ DL NOM/ACC

moj+1U

my PossPron 〈MA $\rangle$ SG ACC

moj+9,i

my PossPron $\langle$ MA $\rangle$ PL NOM

moj+1,U

my PossPron $\langle$ MA $\rangle$ SG NOM

imo

$\mathrm{jIm}+\mathrm{O}$

(verb examples)

to take $\mathrm{V}=\mathrm{prf}=$ PRES SG1

teStI

te. $\mathrm{k}+\mathrm{tU}$

to run, to flow $\mathrm{V}=\mathrm{imp}=\mathrm{SUP}$

grAsU

gre. $b+\dot{S} U$

to row, to $\operatorname{dig} \mathrm{V}=\mathrm{imp}=\mathrm{AOR} \mathrm{SG} 1$

dviZenU

dvig/en $+\mathrm{U}$

to move $\mathrm{V}=\mathrm{prf}=$ PCP PSS PAST INDEF $\langle\mathrm{NE}\rangle$ PL GEN

dvig/en+U

to move $\mathrm{V}=\mathrm{prf}=$ PCP PSS PAST INDEF $\langle\mathrm{FE}\rangle$ PL GEN

$\mathrm{dvig} / \mathrm{en}+\mathrm{U}$

to move $\mathrm{V}=\mathrm{prf}=\mathrm{PCP}$ PSS PAST INDEF $\langle\mathrm{MA}\rangle \mathrm{PL}$ GEN

dvig/en $+\mathrm{U}$

to move $\mathrm{V}=\mathrm{prf}=\mathrm{PCP}$ PSS PAST INDEF $\langle\mathrm{MA}\rangle \mathrm{SG}$ ACC

dvig/en,$+ U$

to move $\mathrm{V}=\mathrm{prf}=$ PCP PSS PAST INDEF $\langle$ MA $\rangle$ SG NOM

\section{nareCeSi}

$\mathrm{na}+\mathrm{re} . \mathrm{ke}+\mathrm{Si}$

to call, to name $\mathrm{V}=\mathrm{prf}=\mathrm{PRES} \mathrm{SG} 2$ 


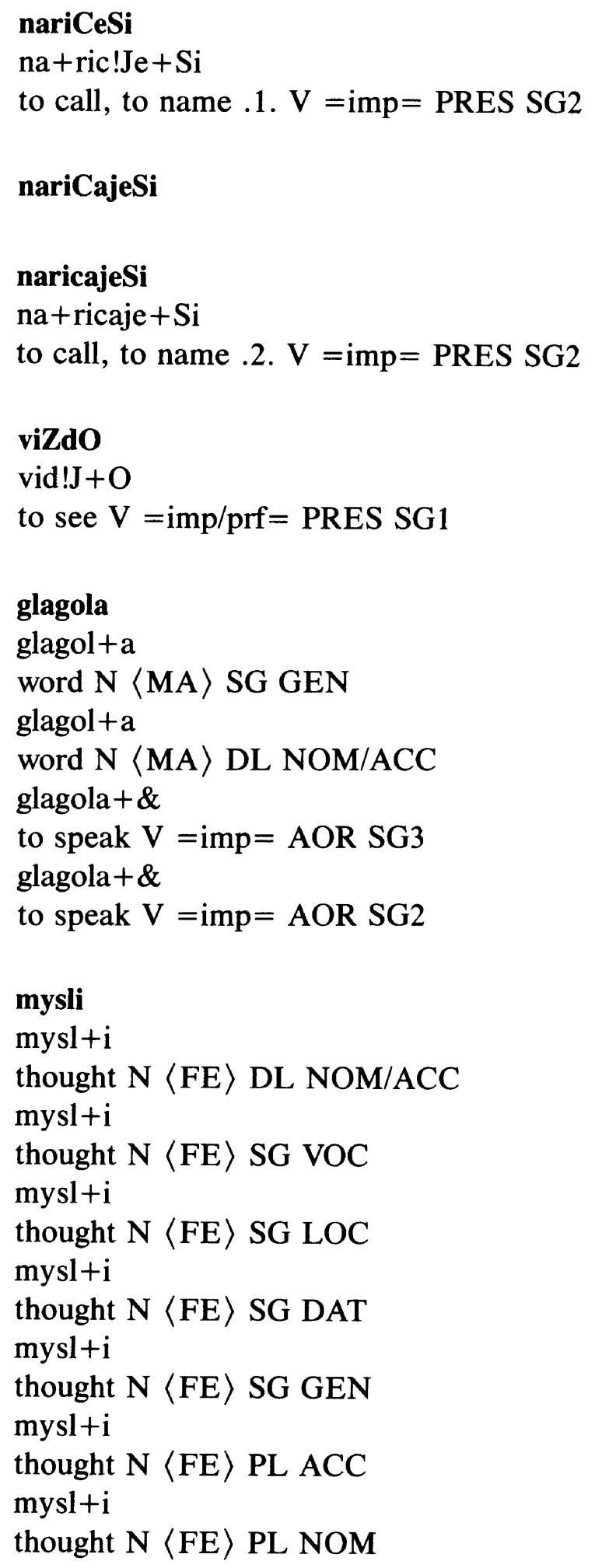


186 Jouko Lindstedt

myslj $+\mathrm{i}$

to think $\mathrm{V}=\mathrm{imp}=\mathrm{IMPV} \mathrm{SG} 2 / 3$

mysli $+\&$

to think $\mathrm{V}=\mathrm{imp}=\mathrm{AOR}$ SG3

mysli $+\&$

to think $\mathrm{V}=\mathrm{imp}=\mathrm{AOR} \mathrm{SG} 2$

tAxU

$t+2 \ddot{A x} U$

that DemPron $\langle\mathrm{FE}\rangle$ PL LOC

$t+2 A ̈ x U$

that DemPron $\langle\mathrm{FE}\rangle$ PL GEN

$t+2 \ddot{A} x U$

that DemPron $\langle\mathrm{NE}\rangle$ PL LOC

$t+2 \ddot{A x} U$

that DemPron $\langle\mathrm{NE}\rangle$ PL GEN

$t+2 \ddot{A x} U$

that DemPron $\langle$ MA $\rangle$ PL LOC

$t+2 \ddot{A x} U$

that DemPron $\langle\mathrm{MA}\rangle$ PL GEN

te. $\mathrm{k}+\dot{S} \mathrm{U}$

to run, to flow $\mathrm{V}=\mathrm{imp}=\mathrm{AOR}$ SG1

duSe

$\mathrm{duS}+\mathrm{o}$

soul, mind $\mathrm{N}\langle\mathrm{FE}\rangle \mathrm{SG}$ VOC

dux +)e

spirit N $\langle$ MA $\rangle$ SG VOC

\section{tAsta}

te.p + Șta

to strike $\mathrm{V}=\mathrm{imp}=\mathrm{AOR}$ DL2

te. $\mathrm{k}+$ Șta

to run, to flow $\mathrm{V}=\mathrm{imp}=\mathrm{AOR} \mathrm{DL} 2$

\section{ZenO}

Zen+O

woman N $\langle\mathrm{FE}\rangle$ SG ACC

gen $+\mathrm{O}$

to chase $\mathrm{V}=\mathrm{imp}=$ PRES SG1 


\section{sAli}

$\mathrm{sA}+1+\mathrm{i}$

to sow .1. V $=i m p=$ PCP ACT PAST2 $\langle\mathrm{MA}\rangle \mathrm{PL}$

sA.d $+1+i$

to sit down $\mathrm{V}=\mathrm{prf}=\mathrm{PCP}$ ACT PAST2 $\langle\mathrm{MA}\rangle \mathrm{PL}$

krai

$\mathrm{kraj}+\ddot{\mathrm{A}}$

(examples of syncretism in paradigms)

edge $\mathrm{N}\langle\mathrm{MA}\rangle \mathrm{SG}$ LOC

kraj $+\mathrm{y}$

edge $\mathrm{N}\langle\mathrm{MA}\rangle \mathrm{PL}$ INS

$\mathrm{kraj}+\mathrm{U}$

edge $N\langle$ MA $\rangle$ PL GEN

$\mathrm{kraj}+\mathrm{U}$

edge N $\langle$ MA $\rangle$ SG ACC

$\mathrm{kraj}+, \mathrm{U}$

edge $N\langle$ MA $\rangle$ SG NOM

$\mathrm{kraj}+, \mathrm{i}$

edge $\mathrm{N}\langle$ MA $\rangle$ PL NOM

velii

velij $+\ddot{\mathrm{A}}$

big, great A INDEF $\langle\mathrm{NE}\rangle$ SG LOC

velij $+y$

big, great A INDEF $\langle$ NE $\rangle$ PL INS

velij+U

big, great A INDEF $\langle\mathrm{NE}\rangle$ PL GEN

velij $+\ddot{\mathrm{A}}$

big, great A INDEF $\langle\mathrm{NE}\rangle \mathrm{DL}$ NOM/ACC

velij+ $\ddot{A}$

big, great A INDEF $\langle$ FE $\rangle$ DL NOM/ACC

velij $+\ddot{\mathrm{A}}$

big, great A INDEF $\langle$ FE $\rangle$ SG LOC

velij $+\ddot{\mathrm{A}}$

big, great A INDEF $\langle$ FE $\rangle$ SG DAT

velij+U

big, great A INDEF $\langle$ FE $\rangle$ PL GEN

velij $+\ddot{\mathrm{A}}$

big, great A INDEF $\langle$ MA $\rangle$ SG LOC 
velij $+y$

big, great A INDEF $\langle$ MA $\rangle$ PL INS

velij+U

big, great A INDEF $\langle$ MA $>$ PL GEN

velij $+\mathrm{U}$

big, great A INDEF 〈MA > SG ACC

velij+, U

big, great A INDEF $\langle$ MA $>$ SG NOM

velij,$+ \mathbf{i}$

big, great A INDEF $\langle$ MA $\rangle$ PL NOM

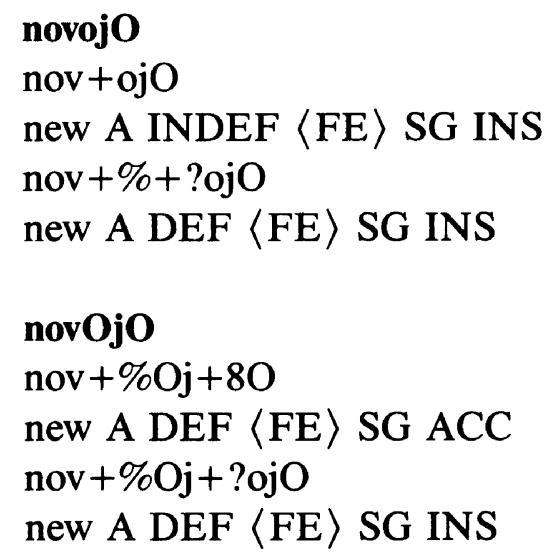

borjemU

bor!Je $+\mathrm{mU}$

to fight, to struggle $\mathrm{V}=\mathrm{imp}=$ PRES PL1

bor!J +om +U

to fight, to struggle $\mathrm{V}=\mathrm{imp}=\mathrm{PCP}$ PSS PRES INDEF $\langle\mathrm{NE}\rangle \mathrm{PL}$ GEN bor!J+om $+\mathrm{U}$

to fight, to struggle $\mathrm{V}=\mathrm{imp}=\mathrm{PCP}$ PSS PRES INDEF $\langle\mathrm{FE}\rangle$ PL GEN bor!J +om $+\mathrm{U}$

to fight, to struggle $\mathrm{V}=\mathrm{imp}=$ PCP PSS PRES INDEF $\langle\mathrm{MA}\rangle \mathrm{PL}$ GEN bor!J +om +U

to fight, to struggle $\mathrm{V}=\mathrm{imp}=$ PCP PSS PRES INDEF $\langle\mathrm{MA}\rangle$ SG ACC bor!J + om,$+ \mathrm{U}$

to fight, to struggle $\mathrm{V}=\mathrm{imp}=$ PCP PSS PRES INDEF $\langle$ MA $\rangle$ SG NOM

\section{dvignOtU}

dvignO $+\mathrm{tU}$

to move $\mathrm{V}=\mathrm{prf}=\mathrm{SUP}$ 
dvign +OtU

to move $\mathrm{V}=$ prf $=$ PRES PL3

(exit the analysis mode)

Quitting Xeq

I

Quitting (Main)

(exit program) 